\title{
The Anti-Nociceptive/Anti-Inflammatory Actions of Botulinum Toxin A for the Treatment of Chronic Pain: A Literature Review
}

\author{
${ }^{1}$ Racha Hajj and ${ }^{2}$ Camille Haddad \\ ${ }^{1}$ Resident, Department of Prosthodontics and Restorative Dentistry, \\ Faculty of Dental Medicine, Saint-Joseph University, Beirut, Lebanon \\ ${ }^{2}$ Assistant Professor, Department of Prosthodontics and Occlusion, \\ Faculty of Dental Medicine, Saint-Joseph University, Beirut, Lebanon
}

\author{
Article history \\ Received: 05-06-2021 \\ Revised: 18-06-2021 \\ Accepted: 08-07-2021 \\ Corresponding author: \\ Racha Haij \\ Resident, Department of \\ Prosthodontics and Restorative \\ Dentistry, \\ Email: rahajj94@gmail.com
}

\begin{abstract}
The aim of this article is to describe the new actions of botulinum toxin A for chronic pain treatment. BT/A inhibits the exocytosis of synaptic vesicles containing the pain mediators neurotransmitters, reduces the post traumatic trigeminal neuralgia pain, inhibits the release of microglia derived TNF- $\alpha$ as well as other pro inflammatory cytokines, viable treatment option in the case of patients who do not respond to conservative treatment methods of chronic pain (medication) BT/A is an emerging treatment for chronic pain; patients with severe chronic facial pain, not responding to conventional treatments, can respond to botulinum type a injections.
\end{abstract}

Keywords: Anti Inflamatory, Anti Nociceptive, BiTox/AA, Botulinum Toxin A, Chronic Pain, Derm-BOT

\section{Introduction}

Botulism is a life-threatening disease caused by a toxin known as botulinum neurotoxin produced by Clostridium Botulinum under anaerobic conditions, as first described by Turner. Botulinum toxin is one of the deadliest toxins known, but it is also used for therapeutic procedures and the range of therapeutic applications is expanding all the time (Srivastava et al., 2015).

The type A botulinum toxin is the most widely used of the many forms of botulinum toxins (Srivastava et al., 2015).

Botulinum Toxin A (BT/A) has been used for esthetic purposes and to regulate painful muscle hyperactivity, myalgia, bruxism, my spasms and parafunctional habits until recently.

Despite the fact that it has been identified as an inhibitor of acetylcholine synaptic exostosis, disabling neural transmission and thus providing an analgesic effect via muscle relaxation/paralysis, its mechanism of action in the treatment of painful conditions such as chronic migraine and Temporo Mandibular Dysfunctions (TMD) pain is still controversial today (Gauer and Semidey, 2015; Ahmad and Schiffman, 2016; De la Torre Canales, 2020a). The mechanism of action on the pain management has bene delineated through a special theory: Though it's renowned that the BT/A contains a high mass and so couldn't reach the central nervous system where all the pain mediators or inhibition are going to be done, several in vivo studies done on rats and paws, showed the bilateral action in distant region once unilateral injection of BT/A closing that peripherally administered $\mathrm{BT} / \mathrm{A}$ might detached to central region via nerve fiber retrograde transport to focus on neurotransmission of pain sensory circuit "the distal retrograde action (Kim et al., 2015; Favre-Guilmard et al., 2009; Xiao et al., 2011; Filipović et al., 2012; Habermann, 1974) a theory still disputable, particularly concerning the experimental conditions and therefore the indefinite quantity of administered toxins (Favre-Guilmard et al., 2009).

Chronic pain is described as a debilitating illness that lasts more than three months and is resistant to traditional conservative treatments.

NSAIDS, opioids and adjuvants including antidepressants and anticonvulsants are the three most common types of medication used to treat chronic pain today.

However, due to their short half-lives or a number of undesirable adverse side effects, such as abuse and overdose, these drugs are largely ineffective or unsuitable for many chronic pain sufferers.

As a result, there is a vital need for long-acting, nonaddictive chronic pain drugs. The BT/A injections are on their way and they may be very effective in achieving the desired treatment result. 
Recent research indicates the development of new hypotheses regarding the BT/A pain-killer function.

Experiments have shown that BT/A has an analgesic effect that is independent of the known motor effect, which has led to new possible indications for BT/A in chronic pain conditions (De la Torre Canales et al., 2020b; Matak and Lacković, 2014; Muñoz-Lora et al., 2017).

Even though numerous systematic reviews of clinical trials provide evidence for BT/A efficacy in other chronic pain conditions, it is not yet well proven and accepted for use in chronic migraine (Safarpour and Jabbari, 2018).

The discovery of new engineered formulations of botulinum toxin commercialized under the name "Bi-tox ${ }^{\circledR}$," with a radically different mode of action from the standard paralytic effect of botulinum toxins and deemed a potential cure for orofacial chronic pain disorders, has resulted in a significant advancement in the field of pain management.

The aim of this article is to review the literature on Botulium Toxin's anti-inflammatory/anti-nociceptive mechanism of action in chronic Orofacial Pain, as well as the newly developed Botulium Toxins (BT) for chronic pain management.

\section{Materials and Methods}

Studies reported between January 2004 and July 2020 that assessed the mechanism of action of BT/A in the treatment of chronic pain were found using the "pub med central" and "Scopus" electronic databases, with English language restrictions.

"Botulinum toxin A," "chronic pain," "antiinflammatory, anti-nociceptive mechanism of action," "new engineered molecules," and "dosage" were among the medical words used in the hunt.

A google scholar quest was also conducted to find other similar studies.
In the initial search, two writers screened the titles and abstracts of the papers that were found. Irrelevant papers were omitted, and prospective articles had to meet inclusion/exclusion requirements in order to be considered for critical assessment.

The following requirements were used to determine eligibility.

Research design:

- Case reports

- Clinical trials, both randomized and quasirandomized

- Reviews of the literature

- Humans who present with a predominant complaint of chronic pain

- Animal Participants

- Intervention: Botulinum toxin type a injections in every place of pain, regardless of dosage

- A control group with some alternative intervention or placebo is needed

- Treatment duration: The short and long-term effects of botulinum toxin A are investigated in this article

- Key outcomes: Pain assessment and botulinum toxin A's antinociceptive/anti-inflammatory mode of action

Exclusion criteria:

- Publications in which type B, C-1, C-2, D, E, F, or G Botox injections are used instead of type $\mathrm{A}$

- Articles that were written prior to 2004

- There is no full text available

The full text versions of the qualifying papers were then reviewed one by one by two examiners.

The studies' findings are listed below, with a table summarizing the findings at the end of the report (Fig. 1).

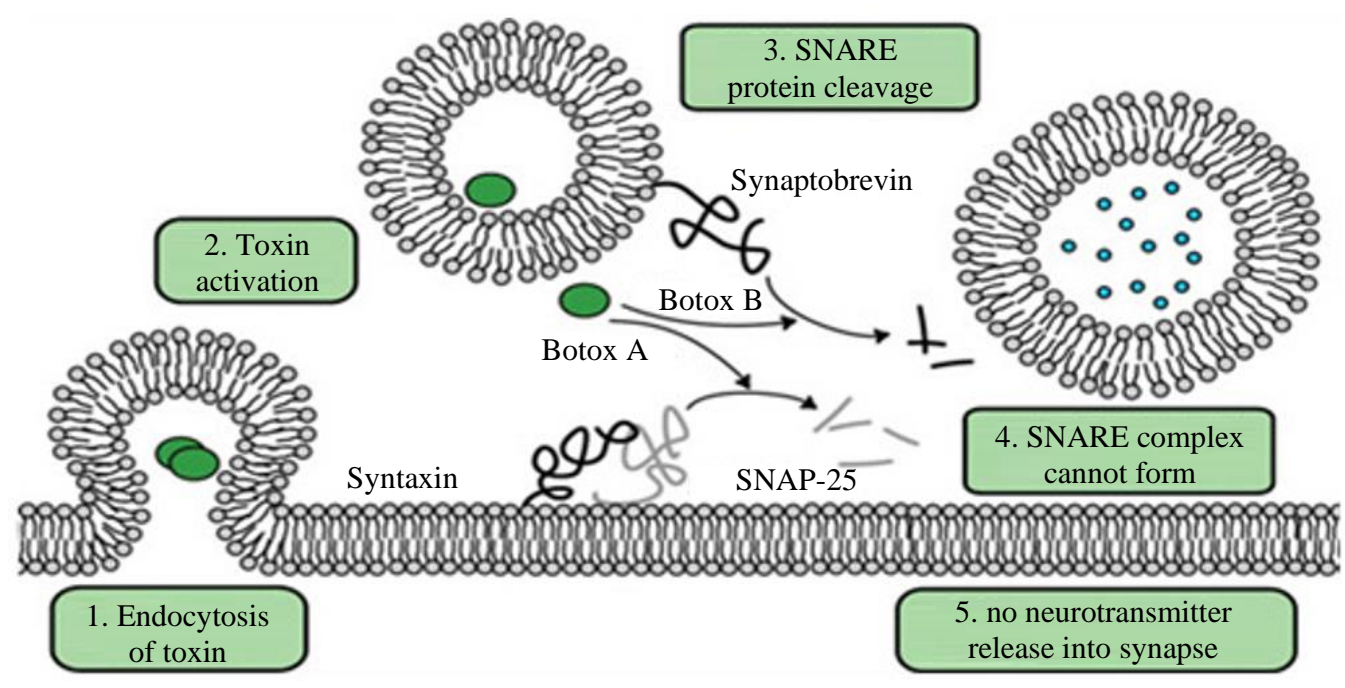

Fig. 1: Mechanism of action of BT/A on SNAREs Craik et al. (2011) 


\section{Results}

\section{Action of BT/A on SNAREs, SNAP25 and VAMP2}

Bin Lu, Uwe Wollina, Dong Wank et al concluded in their studies that BoNTs inhibit the exocytosis of synaptic vesicles containing neurotransmitters of pain mediators by inhibiting the fusion of these vesicles with their target cells (Wollina, 2008; Lu, 2015; Kim et al., 2015).

Botulinum toxin A binds to synaptic terminals and cleaves proteins like SNARE proteins (soluble $\mathrm{N}$ ethylmaleimide-sensitive factor attachment protein receptor complex) due to its active light chain, which is a metalloprotease. These are molecular motors that drive the biological fusion of two membranes (mainly the membrane vesicles and the target cell membrane (Tien et al., 2003) leading to the exocytosis of neurotransmitters.

The Vesicle Associated Membrane Protein (VAMP) and Synaptosomal Associated Protein 25 (SNAP 25) would be blocked if the SNAREs are blocked. The release of various pain-modulating neurotransmitters is mediated by the SNAP 25 proteins (Kim et al., 2015). Botulinum toxins are drawn to the $\mathrm{C}$ terminus of SNAP25.

The mechanism of action of BT/A on SNAREs is summarized in a figure taken from a 2011 article by Craik et al. (2011).

Action of BT/A on Substance P, CGRP and Glutamate (Chuang et al., 2004; Aoki, 2005; Verma, 2013; Barbanti and Ferroni, 2017) (Fig. 2)

Substance $\mathrm{P}$ is a peptide neurotransmitter released by primary nociceptive afferents ( $\mathrm{C}$ fibers) and CGRP is an inflammatory neuropeptide that is contained within dorsal root ganglia neurons and Colocalization with substance $\mathrm{P}$ in most trigeminal and other sensory ganglia neuron.

In a study done by Chuang (2010) on rates, it has been showed that BT/A inhibit substance $\mathrm{P}$ release from cultured embryonic dorsal root ganglion neurons and reduce stimulated (but not basal) release of Calcitonin Gene-Related Peptide (CGRP) from cultured trigeminal ganglia neurons.

Glutamate results in inflammation, pain and edema.

Gurav Verma demonstrated that the injection of $\mathrm{BT} / \mathrm{A}$, in a lower dose than the one needed to induce paralysis, decreases the release of glutamate peripherally and inhibits the inflammatory pain as well as other symptoms (Verma, 2013).

\section{BT/A and Formalin Pain Models (Dickenson and Sullivan, 1987; Cui et al., 2004)}

Formalin is a chemical irritant and therefore, causes pain when injected.

The formalin test is a well-established pre-clinical model that is commonly used to investigate the relation between pain and inflammation following tissue damage. Once Formalin receptors activated, a series of pain neurotransmitters such as glutamate, substance P, CGRP. are released (Dickenson and Sullivan, 1987).

Between the first studies that reports the direct action of BT/A on sensory neurons in vivo, a study done by Cui et al. (2004) on rats demonstrated the antinociceptive effect of subcutaneous injected BT/A by reducing formalin-induced nociceptive behaviors. These antinociceptive effects are associated with the inhibition of formalin-induced release of glutamate (and/or neuropeptides) from primary afferent terminals. It's an interesting study because first, it's the first report showing that BT/A inhibits inflammation-induced pain via direct effects on nociceptive sensory neurons. Second, it demonstrates also the dose - effect relationship: At doses below $30 \mathrm{U} / \mathrm{kg}$, the antinociceptive efficacy was independent of its effects on muscle relaxation. Third, it shows that BT/A plays a role only in chronic pain (phase 2 after formalin stimulation) in which there is release of neurotransmitters whereas it has no effect on acute pain behavior (phase 1) in which excitability and transduction occurs.

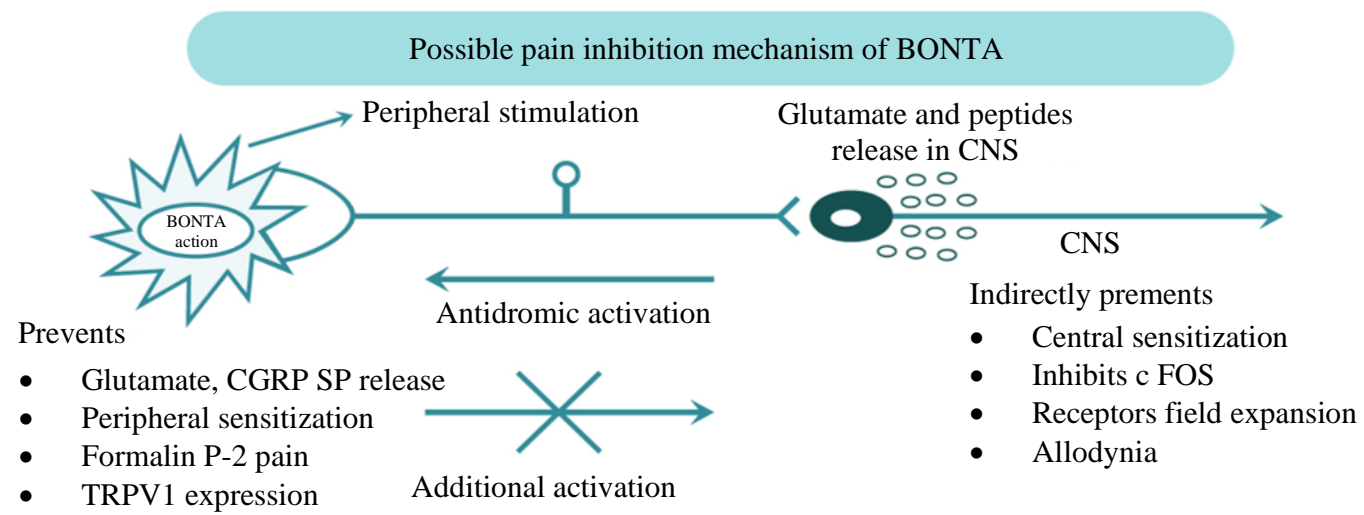

Fig. 2: Proposed mechanism of action of BT/A in pain modulation by inhibiting the release of neurotransmitters and/or neuropeptides from nociceptive neurons, both at central and or peripheral level (Farhan Haq, 2017) 
BT/A in the Treatment of PTTN (De la Torre Canales et al., 2020a; Verma, 2013; Moisset et al., 2020; Egeo et al., 2020; Xu-Dong et al., 2017; Li et al., 2020)

PTTN is known as painful post traumatic trigeminal neuropathy.

In a very recent study done by De la Torre Canales et al. (2020b), they reported the case of a 44 year old woman who presented with 8-years history of pain in the lower left second molar region. After specific exams, the diagnosis was PTTN. After no improvement with conventional pharmalogical treatments, Botox injections were proposed. The patient reported a significant improvement after BT/A intra oral injections in the sites of pain.

Gurav Verma, Moisset $X$ et Ranoux $D$ in their recent articles published in 2020, they reported the positive effect of intra oral BT/A injections in the treatment of PTTN (Moisset et al., 2020; Egeo et al., 2020)

This is also in accordance with other articles mentioned above about the activity of BT/A by preventing the sensory transmitter release in periphery, therefore, inhibiting the release of various nociceptive mediators, such as substance P, glutamate, CGRP and the expression TRPV1 which would justify its used for peripheral neuropathic pain.

The benefit provided by the on botulinum toxin $\mathrm{A}$ was perceived until the 6th month, with no side effects reported by the patient. At the 6th month, pain intensity and quality recurred.

\section{Dosage}

Concerning the dose, till now, there is no consensus about the ideal dosing to achieve a proper therapeutic effect. A systematic review reported that in cases of trigeminal neuralgia, doses ranged from 25 to 100 units divided into 1 to 20 numbers of injections in different sites along the distribution of the trigeminal nerve could be used (Morra et al., 2016).

The guidelines of the Neuropathic Pain Special Interest Group (NeuPSIG) reported the use of BT/A as probably effective and categorized it as third line approach "level C" for PTTN (Cruccu and Truini, 2017) and not the first line treatment due to the lack of consistent evidence coming from well-designed clinical trials.

Kim et al, 2015; Li et al, 2020) reported the antinociceptive action of BT/A when treating a type of post herpetic neuralgia, a type of post traumatic neuralgia, characterized by a constant burning sensation or pain triggered by light, non-painful stimuli.

It's important to mention that in general post traumatic neuralgias are refractory to treatments, may persist for years and therefore affect the patient's quality of life. Finding a treatment such as BT/A for this kind of pain will make a huge change in the patient's life (Xu-Dong et al., 2017; Li et al., 2020).
BT/A and Chronic Inflamation Treatment (Shi et al., 2020)

A novel article written by Shi et al. (2020), reported the anti-inflammatory mechanism of action of botulinum toxin $\mathrm{A}$ in chronic arthritis treatment by inhibiting the activation of microglial cells and the release of microgliaderived TNF- $\alpha$. They explained that in chronic pain, microglial cells are activated. These cells start releasing pro inflammatory cytokines such as interleukin 6, Tumor necrosis factor alpha (TNF alpha) and interleukin 1 betta leading to neuroinflammation. In addition to this, there is receptors called $\mathrm{P} 2 \mathrm{X} 4$ receptors (P2X4Rs) expressed in microglia and involved in neuropathic and inflammatory pain. In this article they have also observed that the BT/A, as an anti-inflammatory treatment, can also alter the regulation of spinal microglial activation by inhibiting spinal microglial P2X4R-P38MAPK intracellular signaling pathways.

So, in chronic inflammation, BT/A can act by inhibiting the release of pro inflammatory cytokins or by inhibiting pain receptors expressed in microglia.

\section{BT/A in the Treatment of Chronic Temporomandibular Disorders (TMD) (Connelly et al., 2017)}

Similar to many other chronic functional pain syndromes, TMD has the potential to become centralized, leading to symptoms that are beyond the control of traditional interventions.

In patient with TMD, pain is the main manifestation and complaint (Ataran et al., 2017).

Connelly et al. (2017) in their article, on retrospective clinical observations taking into consideration many psychological disorders associated with TMD (bruxism, post traumatic syndrome disorder, stress related comorbidities factors, ..), they demonstrated promising mechanism of Botox in the management of chronic TMD, specifically the subgroup of patients with TMD together with stress-related psychiatric comorbidities.

Sipahi et al. (2019) also concluded in their studies that $\mathrm{BT} / \mathrm{A}$ injection is a good treatment option in the case of patients not responding to conventional treatments. Botulinum toxin injection for the treatment of muscular temporomandibular joint disorder is a viable treatment option in the case of patients who do not respond to conservative treatment methods (Ataran et al., 2017).

\section{Molecular Engineering of BT/A Fusion Proteins}

In a recent article written by Minhong $T$, a new approach, consisting of a Protein engineering coretherapeutic to specific targeting ligands is being tested and seems to play an important anti-inflammatory and antinociceptive role (Tang et al., 2020).

Through the application of recombinant DNA and expression techniques, there is an emerging body of literature on the usefulness of such an approach in the 
creation of multi-domain rBTs: Recombinant domains of BT/A with modified properties (Fonfria et al., 2018). One of the recombinant $\mathrm{BT}$ is botulinum molecule with duplicated binding domain-binary toxin-AA called BiTox/AA (Fig. 3). The BiTox/AA is the result of the binding via a SNARE complex formed by complimentary fragments of SNAP-25, VAMP-2 and syntax in of the LHN (BT fragment comprising Light chain and the translocation domain $\mathrm{HN}$ ) and the domain (HC) of BT/A (Kim et al., 2015). BiTox/AA is reported to be non-paralytic with 100 times less when compared to native BT/A following muscle injection, but possesses anti-nociceptive properties (Andreou et al., 2021).

a

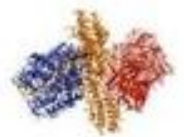

BoNT/A
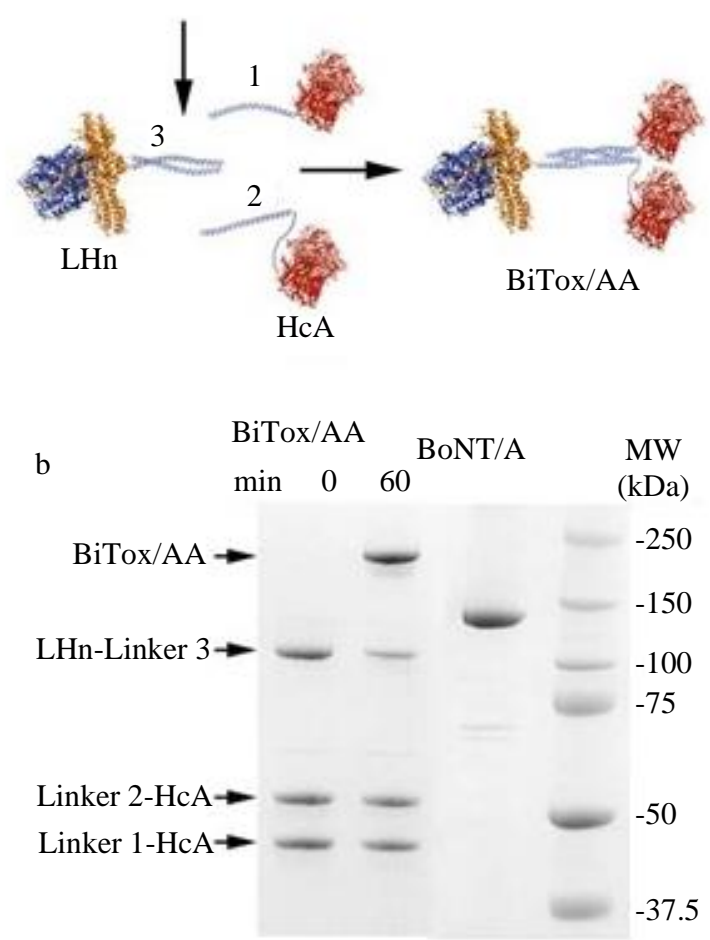

Fig. 3: Synthesis of BiTox/AA. (a) Schematic showing the native BT/A and formation of BiTox/AA from three individual fusion proteins. LHn is the botulinum type A protease with its translocation domain and $\mathrm{HcA}$ is the binding domain of BoNT/A. The three linking peptides form an irreversible complex (light blue). (b) Coomassie-stained SDS-PAGE gel showing the formation of BiTox/AA after the 60-min assembly reaction. The lane indicating $0 \mathrm{~min}$ demonstrates the initial protein amounts used in the BiTox/AA assembly reaction. BiTox/AA exhibits higher molecular weight compared to the native BT/A molecule. Excess amounts of $\mathrm{HcA}$ with linkers 1 and 2 in the lane 60 min migrate at their original positions. Molecular Weight (MW) standards are shown on the right (Andreou et al., 2021)

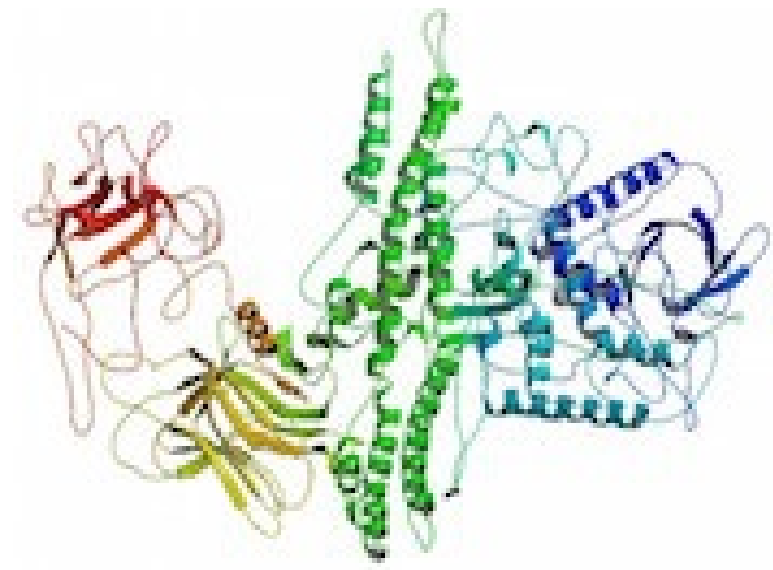

Fig. 4: Protein stapling: a form of LEGO assembly (Sukel, 2013)

It acts effective in attenuating both A-nociceptormediated secondary mechanical hyperalgesia and neuropathic pain in rats, did not reduce $\mathrm{C}$-mediated nociception but inhibited plasma extravasation and inflammatory oedema and reduced keratinocyte proliferation local to the site of toxin injection (Mangione et al., 2016).

In conclusion, Bi-Tox/AA has a potent SNAP-25 cleavage activity but exhibits a reduced paralytic action. This novel botulinum construct showed significant efficacy in animal models in blocking activation of the trigeminal system and in suppressing trigeminal hyperalgesia. This prototype molecule therefore paves the way for a safe preventive treatment for migraine with enhanced therapeutic effects as compared to currently available options (Andreou et al., 2021).

The promising use of Bitox/ AA could be an important molecule in dentistry especially in the treatment of orofacial chronic pain disorders without weakening the muscles and reducing its efficacy, considered as one of the most seen disadvantages of repetitive botulinum toxin injections (Haddad et al., 2020).

Other core engineering Botulinum toxin A molecules were applied on mices, by Davletov's laboratory and the technique called: "Molecular LEGO system", (Crunkhorn, 2018) (Fig. 4) by linking the light chain of BT/A to Substance P (SP) and to Dermophin (Derm) through a protein stapling method using the SNAReS.

The resulting constructs are respectively SP botulinum toxin $(\mathrm{SP}-\mathrm{BOT})^{\circledR}$ and dermophin botulinum toxin (DERM - BOT $)^{\circledR}$.

These new molecules bind to their target opiod receptors, enter the cells, reversibly inhibit the release of neurotransmitters, silencing special targeted neurons for sending pain signals to the brain and therefore produce a long term pain alleviation (Maiarù et al., 2018).

In this way, paralysis, which is the major side effect of botulinum toxins, was removed by targeting specific neurons instead of muscles (Sukel, 2018). 
Table 1: Summary of selected published papers on BT/A and chronic pain

\begin{tabular}{|c|c|c|c|}
\hline Author/ Year & BT/A action studied & Population & Results \\
\hline Dong-Wang et al. (2017) & SNARES protein cleavage & \multirow{3}{*}{ Rats } & \multirow{3}{*}{$\begin{array}{l}\text { BT/A inhibits the exocytosis } \\
\text { of synaptic vesicles containing the }\end{array}$} \\
\hline Wollina (2008) & SNAP 25 cleavage & & \\
\hline $\mathrm{Lu}(2015)$ & pain mediators neurotransmitters & & \\
\hline Chuang et al. (2004) & \multirow[t]{4}{*}{ Substance P, CGRP and Glutamate } & \multirow[t]{4}{*}{ Humans, Rates } & \multirow[t]{4}{*}{ Inflammatory pain reduction. } \\
\hline Aoki (2005) & & & \\
\hline Gaurav (2017) & & & \\
\hline Barbanti et al. (2017) & & & \\
\hline Dickenson et al. (1987) & \multirow[t]{2}{*}{ Formalin } & \multirow[t]{2}{*}{ Rates } & \multirow{8}{*}{$\begin{array}{l}\text { BT/A Reduces formalin-induced } \\
\text { nociceptive behaviors } \\
\text { BONT/A reduces the post traumatic } \\
\text { trigeminal neuralgia pain }\end{array}$} \\
\hline Cui et al. (2004) & & & \\
\hline Canales et al. (2020) & \multirow[t]{6}{*}{ Post traumatic trigeminal neuralgia } & \multirow[t]{6}{*}{ Humans } & \\
\hline Moisset et al. (2020) & & & \\
\hline Ranoux et al. (2020) & & & \\
\hline Gaurav (2013) & & & \\
\hline Ding et al. (2017) & & & \\
\hline Li et al. $(2020)$ & & & \\
\hline Shi et al. (2020) & \multicolumn{2}{|l|}{ Macroglia cells inhibition } & $\begin{array}{l}\text { Bt/A inhibits the release of microglia } \\
\text { derived TNF- } \alpha \text { as well as other pro } \\
\text { inflammatory cytokines }\end{array}$ \\
\hline Connelly et al. (2017) & \multirow{4}{*}{$\begin{array}{l}\text { Temporomandibular chronic } \\
\text { pain disorders }\end{array}$} & \multirow[t]{4}{*}{ Humans } & \multirow{8}{*}{$\begin{array}{l}\text { BT/A injection for the treatment of } \\
\text { muscular temporomandibular joint } \\
\text { disorder is a viable treatment option } \\
\text { in the case of patients who do not } \\
\text { respond to conservative treatment methods. } \\
\text { Pain reduction }\end{array}$} \\
\hline Ataran et al. (2017) & & & \\
\hline Sipahi et al. (2018) & & & \\
\hline & & & \\
\hline Lena et al. (2018) & Molecular engineering of & Rates, mice & \\
\hline Mangione et al. (2016) & new Botulinum toxins & & \\
\hline \multirow[t]{2}{*}{ Crunkhorn (2018) } & BiTOX SP Bot & & \\
\hline & DERM Bot & & \\
\hline
\end{tabular}

Scientists also saw that DERM-BOT was just as effective as morphine in relieving pain (Sukel, 2018).

But according to Davletov, there is much work left to do before this approach could be tested in people

The Table 1 summarizes the most common published papers concerning botulinum toxin $\mathrm{A}$ and its multi-level actions.

\section{Discussion}

BT/A efficacy in chronic migraine was demonstrated in two major industry-sponsored randomized controlled clinical trials (RCTs), after which onabotulinumtoxin A (Botox $\left.{ }^{\circledR}\right)$ was approved by the FDA in 2011 and is still the only approved chronic pain indication (Muñoz-Lora et al., 2017).

The greatest benefits of BT/A use over other traditional and non-conventional analgesic drugs are its prolonged effect after a single treatment due to BT/A protease's ability to resist cellular degradation mechanisms and remain in the cell cytoplasm for a long time (Matak et al., 2019)

Chronic pain is recognized as a significant healthcare concern around the world. Despite the fact that botulinum toxin A can have an anti-inflammatory/anti-nociceptive effect and is increasingly being proposed for chronic pain disorders, the above studies raise several questions.
To begin with, the number of studies performed on individuals is small.

Between the articles mentioned in the table above and many others did their research on rates and mice.

Second, clinical trials are performed with a range of comparator drugs and distinct outcome factors in multiple sore joints... With such a large number of variables, the effect of Botulinium toxin cannot be precisely elaborated and clarified in this way.

Third, in some trials, the same comparator (saline) was used for the same joint in the same cause of chronic pain (Arendt-Nielsen et al., 2017; McAlindon et al., 2018), but the findings were contrary, suggesting that something is lacking in terms of dosage and injection repetition schedule. The severity of the pain can also have an effect on the outcome.

In terms of dosage, there is still no accepted table that summarizes the doses that must be used for each form of chronic pain (chronic headaches, neuralgia.)

Lower doses are often more effective than higher doses. In a double-blind study, (Borodic and Acquadro, 2002) found that using a dose of 25IU for migraine treatment was more successful than using higher doses of $75 \mathrm{IU}$. (37\%) as a result, certain side effects can occur as the dose is increased.

All of these concepts are still hypotheses and more clinical trials with the same variables and injection doses are required. 
Finally, in contrary to the studies mentioned in this article, several research find that botulinum toxins had no anti-inflammatory or anti nociceptive effect as compared to control groups (Mangione et al., 2016; Pellett et al., 2015). in their research, confirmed that BoNT/A has no direct effect on acute, non-inflammatory nociception in humans (Sycha et al., 2006; Matak et al., 2017). An interesting idea was discussed in a recent article published in 2020 by, they found that substance $\mathrm{P}$ plays an important role in the anti-nociceptive action of botulinum toxin A. The deletion of the genes encoding substance $P$ prevented the anti-nociceptive, anti-inflammatory action of botulinm toxin $\mathrm{A}$ in acute, chronic and neuropathic pain (Matak et al., 2017).

\section{Conclusion}

Finally, chronic pain is not a symptom; it is a condition (Gordon et al., 2016; Kalach-Mussali and Algazi, 2018) that is often compounded by care inconsistency. Misunderstanding the nature of symptoms, as well as pessimistic recovery expectations, can cause anxiety and depression, worsening the pain response (De la Torre Canales et al., 2020).

Botulinum toxin can inhibit the release of local nociceptive neuropeptides, neurogenic inflammation and peripheral sensitization in addition to its neuromuscular effects (Chaurand et al., 2021).

In conclusion, botulinum type A injections are an emerging treatment for chronic pain; patients with extreme chronic facial pain who have failed to respond to other treatments may benefit from botulinum type A injections. However, the standard of evidence is not yet high enough to provide physicians with clear recommendations.

More research is required to draw stronger, more definitive conclusions about the mechanism of action and the best dose of Botulinum toxin A to use.

\section{Author's contributions}

The two authors contributed equally in writing the manuscript

\section{Ethics}

The corresponding author confirms that all of the other authors have read and approved the manuscript and no ethical issues involved

\section{References}

Ahmad, M., \& Schiffman, E. L. (2016). Temporomandibular joint disorders and orofacial pain. Dental Clinics of North America, 60(1), 105. https://doi.org/10.1016/j.cden.2015.08.004
Andreou, A. P., Leese, C., Greco, R., Demartini, C., Corrie, E., Simsek, D., ... \& Davletov, B. (2021). Doublebinding botulinum molecule with reduced muscle paralysis: evaluation in in vitro and in vivo models of migraine. Neurotherapeutics, 18(1), 556-568. https://doi.org/10.1007/s13311-020-00967-7

Aoki, K. R. (2005). Review of a proposed mechanism for the antinociceptive action of botulinum toxin type A. Neurotoxicology, 26(5), 785-793. https://doi.org/10.1016/j.neuro.2005.01.017

Arendt-Nielsen, L., Jiang, G. L., DeGryse, R., \& Turkel, C. C. (2017). Intra-articular onabotulinumtoxinA in osteoarthritis knee pain: effect on human mechanistic pain biomarkers and clinical pain. Scandinavian Journal of Rheumatology, 46(4), 303-316. https://doi.org/10.1080/03009742.2016.1203988

Ataran, R., Bahramian, A., Jamali, Z., Pishahang, V., Barzegani, H. S., Sarbakhsh, P., \& Yazdani, J. (2017). The role of botulinum toxin A in treatment of temporomandibular joint disorders: a review. Journal of Dentistry, 18(3), 157.

Barbanti, P., \& Ferroni, P. (2017). Onabotulinum toxin A in the treatment of chronic migraine: patient selection and special considerations. Journal of Pain Research, 10, 2319. https://doi.org/10.2147/JPR.S113614

Borodic, G. E., \& Acquadro, M. A. (2002). The use of botulinum toxin for the treatment of chronic facial pain. The Journal of Pain, 3(1), 21-27. https://doi.org/10.1054/jpai.2002.27142

Chaurand, J., Godínez-Victoria, M., Tellez-Girón, A., Facio-Umaña, J. A., \& Jimenez-Ponce, F. (2021). Incobotulinum toxin type A for treatment of chronic myofascial pain. Journal of Oral Science, 63(1), 37-40. https://doi.org/10.2334/josnusd.20-0090

Chuang, Y. C., Yoshimura, N., Huang, C. C., Chiang, P. H., \& Chancellor, M. B. (2004). Intravesical botulinum toxin a administration produces analgesia against acetic acid induced bladder pain responses in rats. The Journal of urology, 172(4 Part 1), 1529-1532. https://doi.org/10.1097/01.ju.0000137844.77524.97

Connelly, S. T., Myung, J., Gupta, R., Tartaglia, G. M., Gizdulich, A., Yang, J., \& Silva, R. (2017). Clinical outcomes of Botox injections for chronic temporomandibular disorders: do we understand how Botox works on muscle, pain and the brain?. International Journal of oral and Maxillofacial Surgery, 46(3), 322-327. https://doi.org/10.1016/j.ijom.2016.11.004

Craik, C. S., Page, M. J., \& Madison, E. L. (2011). Proteases as therapeutics. Biochemical Journal, 435(1), 1-16. https://doi.org/10.1042/BJ20100965

Cruccu, G., \& Truini, A. (2017). A review of neuropathic pain: From guidelines to clinical practice. Pain and Therapy, 6(1), 35-42. https://doi.org/10.1007/s40122-017-0087-0 
Crunkhorn, S. (2018). Silencing chronic pain with botulinum toxin. Nature Reviews Drug Discovery, 17(9), 620-620. https://doi.org/10.1038/nrd.2018.137

Cui, M., Khanijou, S., Rubino, J., \& Aoki, K. R. (2004). Subcutaneous administration of botulinum toxin A reduces formalin-induced pain. Pain, 107(1-2), 125-133. https://doi.org/10.1016/j.pain.2003.10.008

De la Torre Canales, G., Alvarez-Pinzon, N., MuñozLora, V. R. M., Vieira Peroni, L., Farias Gomes, A., Sánchez-Ayala, A., ... \& Rizzatti-Barbosa, C. M. (2020a). Efficacy and safety of botulinum toxin type a on persistent myofascial pain: A randomized clinical trial. Toxins, 12(6), 395. https://doi.org/10.3390/toxins 12060395

De la Torre Canales, G., Poluha, R. L., Ferreira, D. M., Stuginski-Barbosa, J., \& Conti, P. C. R. (2020b). Botulinum toxin-A injections as therapy for chronic painful post-traumatic trigeminal neuropathy: case report. Brazilian Dental Science, 23(1), 5-p. https://doi.org/10.14295/bds.2020.v23i1.1800

Dickenson, A. H., \& Sullivan, A. F. (1987). Peripheral origins and central modulation of subcutaneous formalin-induced activity of rat dorsal horn neurones. Neuroscience Letters, 83(1-2), 207-211. https://doi.org/10.1016/0304-3940(87)90242-4

Egeo, G., Fofi, L., \& Barbanti, P. (2020). Botulinum neurotoxin for the treatment of neuropathic pain. Frontiers in Neurology, 11, 716. https://doi.org/10.3389/fneur.2020.00716

Farhan Haq, A. (2017). Botox in pain management. The cosmetic doctor journals.2017

https://www.theharleystreet.com/journal/botox-inpain-management/

Favre-Guilmard, C., Auguet, M., \& Chabrier, P. E. (2009). Different antinociceptive effects of botulinum toxin type $\mathrm{A}$ in inflammatory and peripheral polyneuropathic rat models. European Journal of Pharmacology, 617(1-3), 48-53. https://doi.org/10.1016/j.ejphar.2009.06.047

Filipović, B., Matak, I., Bach-Rojecky, L., \& Lacković, Z. (2012). Central action of peripherally applied botulinum toxin type $\mathrm{A}$ on pain and dural protein extravasation in rat model of trigeminal neuropathy. PLoS One, 7(1), e29803. https://doi.org/10.1371/journal.pone.0029803

Fonfria, E., Elliott, M., Beard, M., Chaddock, J. A., \& Krupp, J. (2018). Engineering botulinum toxins to improve and expand targeting and SNARE cleavage activity. Toxins, 10(7), 278. https://doi.org/10.3390/toxins10070278

Gauer, R. L., \& Semidey, M. J. (2015). Diagnosis and Treatment of Temporomandibular Disorders. Family Physician Membership Journal, 91(6), 378-386. https://europepmc.org/article/med/25822556
Gordon, D., Ko, Ian, F., \& Brian, F. (2016). Botulinum Toxin Type-A in Pain Management. A review of BTXA including a discussion of its mode of action and case studies illustrating its use in treatment of a variety of pain presentations. Practical Pain Management, 8(8).

Habermann, E. (1974). 125 I-labeled neurotoxin from Clostridium botulinum A: preparation, binding to synaptosomes and ascent to the spinal cord. NaunynSchmiedeberg's Archives of Pharmacology, 281(1), 47-56. https://doi.org/10.1007/BF00500611

Haddad, C., Mrad, S., \& El Najjar, G. (2020). Adverse Effects of Botulinum Toxin type-A injections in masticatory muscles on underlying bone and cartilage: a literature review. International Arab Journal of Dentistry, 11(1).

Kalach-Mussali, A. J., \& Algazi, D. M. (2018). Toxin for the Treatment of Chronic Migraines. $5^{\text {th }}$ edition.2018:110-111. https://doi.org/10.5772/intechopen.78777

Kim, D. W., Lee, S. K., \& Ahnn, J. (2015). Botulinum toxin as a pain killer: players and actions in antinociception. Toxins, 7(7), 2435-2453. https://doi.org/10.3390/toxins7072435

Li, X. L., Zeng, X., Zeng, S., He, H. P., Zeng, Z., Peng, L. L., \& Chen, L. G. (2020). Botulinum toxin A treatment for post-herpetic neuralgia: A systematic review and meta-analysis. Experimental and Therapeutic Medicine, 19(2), 1058-1064. https://doi.org/10.3892/etm.2019.8301

Lu, B. (2015). The destructive effect of botulinum neurotoxins on the SNARE protein: SNAP-25 and synaptic membrane fusion. Peer Journal, 3, e1065. https://doi.org/10.7717/peerj.1065

Maiarù, M., Leese, C., Certo, M., Echeverria-Altuna, I., Mangione, A. S., Arsenault, J., ... \& Hunt, S. P. (2018). Selective neuronal silencing using synthetic botulinum molecules alleviates chronic pain in mice. Science Translational Medicine, 10(450). https://doi.org/10.1126/scitranslmed.aar7384

Mangione, A. S., Obara, I., Maiarú, M., Geranton, S. M., Tassorelli, C., Ferrari, E., ... \& Hunt, S. P. (2016). Nonparalytic botulinum molecules for the control of pain. Pain, 157(5), 1045. https://doi.org/10.1097/j.pain.0000000000000478.

Matak, I., \& Lacković, Z. (2014). Botulinum toxin A, brain and pain. Progress in Neurobiology, 119, 39-59. https://doi.org/10.1016/j.pneurobio.2014.06.001

Matak, I., Bölcskei, K., Bach-Rojecky, L., \& Helyes, Z. (2019). Mechanisms of botulinum toxin type A action on pain. Toxins, 11(8), 459. https://doi.org/10.3390/toxins11080459 
Matak, I., Tékus, V., Bölcskei, K., Lacković, Z., \& Helyes, Z. (2017). Involvement of substance P in the antinociceptive effect of botulinum toxin type A: Evidence from knockout mice. Neuroscience, 358, 137-145. https://doi.org/10.1016/j.neuroscience.2017.06.040

McAlindon, T. E., Schmidt, U., Bugarin, D., Abrams, S., Geib, T., DeGryse, R. E., ... \& Schnitzer, T. J. (2018). Efficacy and safety of single-dose onabotulinumtoxinA in the treatment of symptoms of osteoarthritis of the knee: Results of a placebocontrolled, double-blind study. Osteoarthritis and Cartilage, 26(10), 1291-1299. https://doi.org/10.1016/j.joca.2018.05.001

Moisset, X., Bouhassira, D., Couturier, J. A., Alchaar, H., Conradi, S., Delmotte, M. H., ... \& Attal, N. (2020). Pharmacological and non-pharmacological treatments for neuropathic pain: systematic review and French recommendations. Revue Neurologique, 176(5), 325-352. https://doi.org/10.1016/j.neurol.2020.01.361

Morra, M. E., Elgebaly, A., Elmaraezy, A., Khalil, A. M., Altibi, A. M., Vu, T. L. H., ... \& Hirayama, K. (2016). Therapeutic efficacy and safety of Botulinum Toxin A Therapy in Trigeminal Neuralgia: A systematic review and meta-analysis of randomized controlled trials. The Journal of Headache and Pain, 17(1), 1-9. https://doi.org/10.1186/s10194-016-0651-8

Muñoz-Lora, V. R. M., Clemente-Napimoga, J. T., \& Ballassini, H. (2017). Gomes-Macedo C. De la Torre Canales G. and Rizzatti- Barbosa C.M. Botulinum toxin type A reduces inflammatory hyper nociception induced by arthritis in the temporomandibular joint of rats. Toxicon,129, 52-57. https://doi.org/10.1016/j.toxicon.2017.02.010

Pellett, S., Yaksh, T. L., \& Ramachandran, R. (2015). Current status and future directions of botulinum neurotoxins for targeting pain processing. Toxins, 7(11), 4519-4563. https://doi.org/10.3390/toxins7114519

Safarpour, Y., \& Jabbari, B. (2018). Botulinum toxin treatment of pain syndromes-an evidence based review. Toxicon, 147, 120-128. https://doi.org/10.1016/j.toxicon.2018.01.017

Shi, X., Gao, C., Wang, L., Chu, X., Shi, Q., Yang, H., \& $\mathrm{Li}$, T. (2020). Botulinum toxin type A ameliorates adjuvant-arthritis pain by inhibiting microglial activation-mediated neuroinflammation and intracellular molecular signaling. Toxicon, 178, 33-40. https://doi.org/10.1016/j.toxicon.2019.12.153

Srivastava, S., Kharbanda, S., Pal, U. S., \& Shah, V. (2015). Applications of botulinum toxin in dentistry: A comprehensive review. National Journal of Maxillofacial Surgery, 6(2), 152. https://doi.org/10.4103/0975-5950.183860
Sukel, K. (2018). Modified Botulinum Molecules Ease Pain in Mouse Models. New constructs target spinal NK1R-expressing neurons, or mu opioid receptorcontaining cells, to relieve inflammatory and neuropathic pain. Pain research forum. 2018.

Sycha, T., Samal, D., Chizh, B., Lehr, S., Gustorff, B., Schnider, P., \& Auff, E. (2006). A lack of antinociceptive or antiinflammatory effect of botulinum toxin $\mathrm{A}$ in an inflammatory human pain model. Anesthesia \& Analgesia, 102(2), 509-516. https://doi.org/10.1213/01.ane.0000194447.46763.73

Tang, M., Meng, J., \& Wang, J. (2020). New engineeredbotulinum toxins inhibit the release of pain-related mediators. International Journal of Molecular Sciences, 21(1), 262. https://doi.org/10.3390/ijms21010262

Verma, G. (2013). Role of botulinum toxin type-A (BTXA) in the management of trigeminal neuralgia. Pain Research and Treatment, 2013. https://doi.org/10.1155/2013/831094

Wollina, U. (2008). Botulinum toxin: Non-cosmetic indications and possible mechanisms of action. Journal of Cutaneous and Aesthetic Surgery, 1(1), 3. https://doi.org/10.4103/0974-2077.41148

Xiao, L., Chen, J., Da, J., \& Zhang, D. (2011). Botulinum toxin decreases hyperalgesia and inhibits P2X3 receptor over-expression in sensory neurons induced by ventral root transection in rats. Pain Medicine. 12, 1385-1394. https://doi.org/10.3390/toxins7072435

Xu-Dong, D. I. N. G., Zhong, J., Yan-Ping, L. I. U., \& Hua-Xian, C. H. E. N. (2017). Botulinum as a toxin for treating post-herpetic neuralgia. Iranian Journal of Public Health, 46(5), 608.

Tang, M., Meng, J., \& Wang, J. (2019). New EngineeredBotulinum Toxins Inhibit the Release of Pain-Related Mediators. International Journal of Molecular Sciences, 21(1), 262. https://doi.org/10.3390/ijms21010262

Chuang, Y.CH., Kuo, H. \& Chancellor, M. (2010).Botulinum toxin for the lower urinary tract. BJUI Journal, 105(8), 1046-1058 https://doi.org/10.1111/j.1464-410X.2010.09317.x

Li, X. L., Zeng, X., Zeng, S., He, H. P., Zeng, Z., Peng, L. L., \& Chen, L. G. (2020). Botulinum toxin A treatment for post-herpetic neuralgia: A systematic review and meta-analysis. Experimental and Therapeutic Medicine, 19(2), 1058-1064. https://doi.org/10.3892/etm.2019.8301

Sipahi Calis A, Colakoglu Z, Gunbay S. (2019). The use of botulinum toxin-a in the treatment of muscular temporomandibular joint disorders. J Stomatol Oral Maxillofac Surgery, 120(4) 22-325. https://doi.org/10.1016/j.jormas.2019.02.015. 